\title{
A Study on use of Search Engine Optimization with Reference to Sarvana Paints, Kolhapur
}

\author{
Miss. Shreya. M. Kittur¹, Mrs. Madhura. K. Mane² \\ ${ }^{1}$ Student, Department of Management, ${ }^{2}$ MBA, MCA, M.Phil, M.Com \\ ${ }^{1,2}$ Chhatrapati Shahu Institute of Business Education and Research, \\ Shivaji University, Kolhapur, Maharashtra, India
}

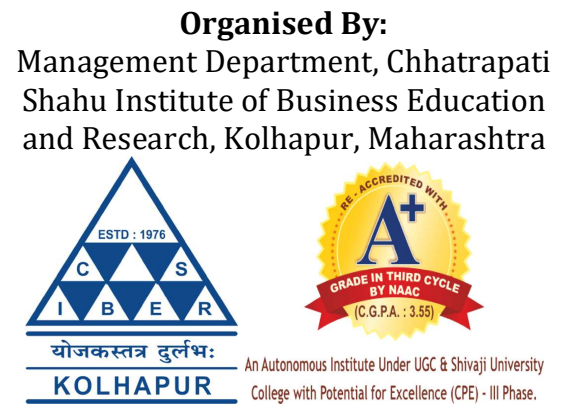

How to cite this paper: Miss. Shreya. M. Kittur | Mrs. Madhura. K. Mane "A Study on use of Search Engine Optimization with Reference to Sarvana Paints, Kolhapur" Published in International Journal of Trend in Scientific Research and Development (ijtsrd), ISSN: 24566470, Special Issue | Fostering Innovation, Integration and Inclusion Through

Interdisciplinary

Practices in

Management, March

2019, pp.218-221,

URL:

https://www.ijtsrd.c om/papers/ijtsrd23 106.pdf

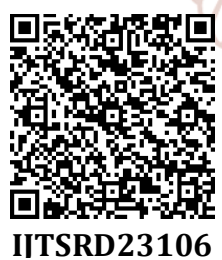

\section{ABSTRACT}

In today's world of internet there are many opportunities for businesses. Using internet, one can earn customers for one's business and reach them conveniently. In today's competitive world, instead of traditional marketing, modern marketing technologies are being used like Search Engine Optimization. Search engine optimization is simply the process of obtaining website visitors from - free\| search results in search engines. In this we try to understand the procedure of Search Engine Optimization and implement it on Sarvana Paints, study the level of Search Engine Optimization achieved by Sarvana Paints and to promote Sarvana paints products digitally. The purpose of SEO is to increase website traffic, increase sales leads, increase sales revenue, repeat visitors, SEO allows to measure the amount of visit activity of an user to a particular website which helps to increase website traffic. The methodology used for this study is data collection from company website and also on the survey conducted on paint industries in Kolhapur. From this study it can be concluded that as Sarvana paints is a startup company people are aware of its products and services. Company's brand is a valuable asset, especially if you have put a significant amount of resources into developing it. Actually, increasing and improving brand awareness is one of the top priorities for marketers .So SEO is an effective tool for Digital Marketing. It helps in increasing the ranking of webpage. It is useful for the companies to achieve success in terms of brand name. So this company is implementing SEO techniques due to which it will create Sarvana products awareness, increase website traffic, increase ranking of Sarvana Paints website page, repeat the visitors visiting Sarvana Paints website, to increase sales of Sarvana Paints.

\section{INTRODUCTION}

The speed of digital media is fast and hence it is helping to expand the business .Digital marketing's is being developed since the 1990s and now it uses new technology for marketing. As compared to traditional marketing, digital marketing is prevalent and efficient in all business fields because now-a-days everyone uses a smart phone so it becomes convenient for people to do shopping digitally. The traditional marketing involved businesses which could advertise their products or services on print media, radio and television commercials, business cards, bill boards, and in many other similar ways where Internet or social media websites were not employed for advertising. Traditional marketing is limited customer reach ability and scope of driving customers' buying behavior. In today's competitive world, instead of traditional marketing, modern marketing technologies are being used like Search Engine Optimization.
Search engine optimization is simply the process of obtaining website visitors (or traffic) from - free\| search results in search engines. Digital marketing is the marketing of products or services using digital technologies, mainly on the internet but also including mobile phones, display advertising, and any other digital medium.

\section{SEARCH ENGINE OPTIMIZATION}

Search Engine Optimization is a methodology of strategies, techniques and tactics used to increase the amount of visitors to a website by obtaining a high-ranking placement in the search results page of a search engine (SERP) including Google, Bing, Yahoo and other search engine.

Search engine optimization (SEO for short) is the process of obtaining website visitors from -free\| search results in 
search engines. All major search engines have primary search results that are ranked based on what the search engine considers most relevant to users. We call these organic results, because they are free and not driven by paid advertisements.

SEO will help to maximize the number of visitors to a particular website or page by ensuring that the site appears high on the list of organic results returned by a given search engine.

\section{OBJECTIVE OF STUDY}

The broad objective is to understand the procedure of Search Engine Optimization and implement it on Sarvana Paints, study the level of Search Engine Optimization achieved by Sarvana Paints and to promote Sarvana paints products digitally. The purpose of SEO is to increase website traffic, increase sales leads, increase sales revenue, repeat visitors , SEO allows to measure the amount of visit activity of an user to a particular website which helps to increase website traffic.

\section{SCOPE AND LIMITATIONS OF THE STUDY}

The scope of the present study is limiting to the use of search engine optimization techniques to optimize search for Sarvana paints on Google search engine only by using tools like Google search Console and Keyword Planner. Limitations are as follows

1. The results are based on the assumption that information provided by the company was correct.

2. The limited period of time i.e.60 days.

3. The response of customers from only Kolhapur city were considered.

4. For security purpose, some original data is not displayed in the report.

\section{METHODOLOGY}

The research study is based on primary \& secondary data. Primary data has been collected from 30 customers of paint companies in Kolhapur. Secondary data has been collected from company website. So using secondary data, SEO technique can be applied on it.

\section{LITERATURE REVIEW}

1. ShikhaGoel et al. -Search Engine Evaluation Based on Page Level Keywords || (2012), this Paper highlights the approach of Search Engine evaluation which is based on page level keywords. Page level keywords are the keywords found in individual pages of website. Page level keyword is an impotent factor to measure the relevance of Search Engine results. A user create a query and Search Engine designer design the database for this query and later the queries are run by the users to calculate the page level keywords and the results are calculated. Keywords are grouping of words that user use to find products on Search Engine. A keyword can be any word on page but a stop word can't be a keyword for web page. Page level keywords include Title, header, and first word of title page, anchor text, page $\mathrm{H} 1$ tag, Meta description, image file name, ALT tags, and Page's URL string. Search Engine parse all the keywords from web page and create a database to store them into database. User's query indirectly evaluate on the dataset instead of web page. A relevant keywords occurrence count by Search Engine. A web page with higher occurrence of keywords takes high ranking in the search results.

2. John B. Killoranet al. - How to use Search Engine optimization techniques to Increase website visibility\| (2013), This research paper highlights the two key points the =key concepts' key lessons' to increase the website visibility using Search Engine Optimization Techniques. Professional point to some content on the web for themselves and or clients on websites they maintained. They use website title, key phrase, name of website, or name of organization that owns it. What contributes to Search Engine rankings? What can web content creators and webmasters do on their pages, sites and the web to make their content and sites easier to find by audience. Search rankings enable web content creators to continually monitor the exact measure of their competitive fitness and lacks for any given queries. Some websites content creators create their sites mainly directing their site for Search Engine ranking rules, not for human audience. Search Engine increase site ranking on the basis of their authenticity, topicality and quality, especially popularity. Two main factors affect SEO are, Trust - of which page rank is only the well know component, Relevance - a website topically matches with a particular query.

3. Zhou Hui, et al. -Study on Website Search Engine Optimization// (2012), this research paper highlights the Search Engine work principal. This research paper highlights the following contents of Search Engine optimization, Principal of Search Engine, Factors affecting search ranking, Method of website Search Engine optimization. Search Engine optimization points out the web page coding, web page content, web constitution, which describe how Search Engine work on web pages ranking strategies. Search Engine includes 21 following three categories: Full text Search Engine, Meta Search Engine, Directory Search Engine. Factor effecting search Ranking: three major factors include Webpage correlation: - determine the degree of keyword matching, keyword density, keyword distribution, and webpage tag labels. Link weight: - determine the internal link weights and the external link weight. Timebased factors: - includes the website and web page age, link age and the length of domain name registration time. Methods of websites Search Engine optimization are Keyword Optimization, Website content optimization, Website structure optimization, Webpage optimization, Link Optimization includes, Internal Links, Outgoing links, Incoming Links. Website submission includes, Submit to Search Engine, Submit to open directory library.

\section{DATA ANALYSIS AND INTERPRETATION:}

Based on the survey conducted using primary data by questionnaire method to understand the product awareness of Sarvana Paints following were the results: 
International Journal of Trend in Scientific Research and Development (IJTSRD) @ www.ijtsrd.com eISSN: 2456-6470

\begin{tabular}{|c|c|c|c|}
\hline $\begin{array}{l}\text { Sr. } \\
\text { No. }\end{array}$ & Factors & $\begin{array}{c}\text { No. Of } \\
\text { Respondents }\end{array}$ & Percentage \\
\hline \multirow{6}{*}{1} & \multicolumn{3}{|c|}{ Brand Awareness } \\
\hline & I. Asian Paints & 12 & $40 \%$ \\
\hline & II. Nerolac & 10 & $33.33 \%$ \\
\hline & III. Berger & 5 & $16.66 \%$ \\
\hline & IV. Dulux & 2 & $6.66 \%$ \\
\hline & V. Indigo & 1 & $3.33 \%$ \\
\hline \multirow{4}{*}{2} & \multicolumn{3}{|c|}{ Factor choosen } \\
\hline & I. Brand Name & 15 & $50 \%$ \\
\hline & II. Quality & 13 & $32 \%$ \\
\hline & $\begin{array}{l}\text { III. Other } \\
\text { facilities }\end{array}$ & 2 & $8 \%$ \\
\hline \multirow{5}{*}{3} & \multicolumn{3}{|c|}{ Brand Awareness Mediums } \\
\hline & I. Painter & 14 & $47 \%$ \\
\hline & II. Advertising & 8 & $26 \%$ \\
\hline & $\begin{array}{c}\text { III. Social } \\
\text { Media } \\
\end{array}$ & 6 & $20 \%$ \\
\hline & IV. References & 2 & $7 \%$ \\
\hline \multirow{3}{*}{4} & \multicolumn{3}{|c|}{ Awareness about Sarvana Paints } \\
\hline & I.Yes & 3 & $10 \%$ \\
\hline & II. No & 27 & $90 \%$ \\
\hline
\end{tabular}

Mostly consumers use the paint which is recommended by painters. But even painters don't know about Sarvana paints. The factors responsible for choosing a paint is mostly the brand name .So famous companies like Asian, Nerolac, Berger are mostly used. So from this we can say that as Sarvana paints is a startup company, many of them are not aware about its product offering in the market. So in order to increase the brand awareness digitally search engine optimization technique is being used which is further described.

\section{Use of SEO technique on secondary data}

Through research it can be seen that customers are not aware of Sarvana paints products, so they do not search for it on Google search engine. In order to achieve search optimization, Sarvana paints name should be seen on 1 st page of Google search so Search engine optimization technique is used.

Google search: When we search for paint industries in Google search bar, there are list of industries displayed by Google search like Asian Paints ,Nerolac Paints but Sarvana paints name is not displayed. It is because Asian paints website has source code in which meta tags contain the keywords related to paint but this is missing in Sarvana Paints website.

Asian Paints is displayed because keywords related to paint are used in the meta tags like: "Wall Paints, House wall paints, house colours, home painting, house paints, paints India, paint company get house wall painting colours from the largest paint manufacturer company in India

\section{FINDINGS:}

$>$ From the study we come to know that, among the total no. of respondents, $40 \%$ use Asian paints, then followed by Nerolac paints $33 \%$, and so on. But there no use of Sarvana paint because people are not aware about its products and services

$>$ In Kolhapur, customers using a particular brand based on its brand name are $50 \%$, so as when there is awareness of a product then only people will use that product, so Sarvana paints products must be reached to most of the customers so that even they can benefit from that brand.

$>$ Most of the customers come to know about which paint to use from their painters which come to their house to color. So the painters must also be aware of Sarvana paints so that they can suggest it to customers.

$>$ People use a particular brand once again when they are satisfied with its quality $n$ effectiveness from 1st try use. So among the respondents most of them using the same brand atleast 5 times is highest. As Sarvana paints is not used once also people don't know about its quality and durability.

$>$ Out of the total respondents , $90 \%$ have said that they have not heard about Sarvana paints anywhere. So there is need to do Search engine optimization of this paint company.

\section{Findings from secondary data:}

Sarvana paints name cannot be seen anywhere on the $1^{\text {st }}$ page as people are not aware about it. So in order to bring it on first page of Google and to increase its ranking, and product awareness, Search engine optimization techniques is used over here using the following tools .

\section{SUGGESTIONS}

Company should try to attract more no. of customers by advertising of their product. Tools of SEO like Google Search Console and Keyword Planner can be used over here.

Tools to be used:

1. Google Search Console

1. Search Console tools and reports help you measure your site's Search traffic and performance, fix issues, and make your site shine in Google Search results.

2. See which keywords bring users to your site. Analyze your site's impressions, clicks, and position on Google Search.

3. Submit sitemaps and individual URLs for crawling. Review your index coverage to make sure that Google has the freshest view of your site.

4. The URL Inspection tool provides detailed crawl, index, and serving information about your pages, directly from the Google index.

5. Optimize and enhance your site

\section{Keyword Planner}

Keyword Planner Tool will help you discover thousands of new long-tail keywords related to any topic by automatically generating Google's search suggestions. The keyword suggestions will be produced based on a Google domain and language that you choose. Using this keyword can be search related to paint:

"keywords" content="wall paints, house colours, home painting, house paints, Paint Store, Paint and Wallpaper, Trade Centre, Colour Trends, Paint mixing, paint supplier, coatings supplier. .

\section{EXPECTED RESULTS AFTER USING SEO :}

$>$ When these keywords are typed in Google search bar, name of Sarvana paints will be shown along with other paint companies names.

$>$ Time for optimization: 7 to 8 months. 
International Journal of Trend in Scientific Research and Development (IJTSRD) @ www.ijtsrd.com eISSN: 2456-6470

$>$ To optimizes Sarvana paints search results the company has to always update digital posters

$>$ related to paints on social media sites.

\section{CONCLUSION}

From this study it can be concluded that as Sarvana paints is a startup company people are aware of its products and services. Company's brand is a valuable asset, especially if you have put a significant amount of resources into developing it and to reach at global level. Actually, increasing and improving brand awareness is one of the top priorities for marketers using various techniques. So SEO is an effective tool for Digital Marketing. It helps in increasing the ranking of webpage. It is useful for the companies to achieve success in terms of brand name. So this company is implementing SEO techniques due to which it will Create Sarvana Products awareness, increase website traffic, increase ranking of Sarvana Paints website page, Repeat the visitors visiting Sarvana Paints website, to increase sales of Sarvana Paints.

\section{REFERENCES}

\section{Books:}

[1] Ahuja, V. (2017).Digital Marketing. Noida: Oxford publication

[2] Asif, S. (2016).Google Analytics Breakthrough. Wiley publication.

[3] Aspatore, J. (2010). Digital Rush. Amacom publication.

[4] Diamond, S. (2013). Web Marketing for Small Business. Source books Inc.

[5] Dodson, I. (2016). The Art Of Digital Marketing. Wiley publication.
[6] Hemann, C. (2009). Digital Marketing Analytics: Making Sense of Consumer Data in a Digital World. Pearson publication.

[7] Kotler, P. (2010). A Book on Marketing. Pearson publication.

[8] Njoroge, G. (2014). Advanced Digital Marketing(Complete Ads Guide). Pearson publication,.

[9] Sharma, D. R. (2010).Digital Marketing current trends .DND publication.

\section{Journals:}

[1] Khraim, H. S. (2015). The Impact of Search Engine Optimization Dimensions on Companies Using American Journal of Business and Management, 9.

[2] Vinit Kumar Gunjan, M. J. (2012). Search engine optimization with Google . IJCSI International Journal of Computer Science Issues, 8.

\section{Internet Sources}

[1] https://google search-consol.com

[2] https://www.techwyse.com/.marketing/52-digitalmarketing-to-grow-your-knowledge.

[3] www.sarvanapaints

Copyright (C) 2019 by author(s) and International Journal of Trend in Scientific Research and Development

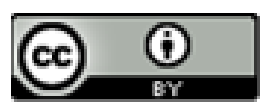
Journal. This is an Open Access article distributed under the terms of the Creative Commons Attribution License (CC BY 4.0) (http://creativecommons.org/licenses/by/4.0) 